\title{
DGAI verleiht Wissenschaftspreise
}

\author{
Anläßlich der 21. Tagung der Deutschen Gesellschaft für \\ Allergologie und klinische Immunologie (DGAl) im Oktober \\ dieses Jahres in München verlieh die DGAI wiederum \\ wichtige Preise, die für herausragende Arbeiten bzw. \\ Publikationen auf dem Gebiet der Allergologie \\ und klinischen Immunologie vergeben werden.
}

\section{Herbert-Herxheimer-Förderpreis}

Der Herbert-Herxheimer-Förderpreis der Deutschen Gesellschaft für Allergologie und klinische Immunologie wird jüngeren Nachwuchswissenschaftlern bis zu einem Alter von 40 Jahren für eine herausragende Originalarbeit auf dem Gebiet der Allergologie und klinischen Immunologie, die im Verlauf des vergangenen Jahres publiziert worden ist, verliehen.

Der Preis war in diesem Jahr mit insgesamt 8000,-- DM dotiert und zu gleichen Teilen für eine Publikation aus der klinisch angewandten Forschung sowie aus der experimentellen allergologisch-immunologischen Forschung ausgeschrieben.

Entgegennehmen konnten diesen
Preis G. Schramm mit ihrer Arbeit „Allergen Engineering: Variants of the Timothy Grass Pollen Allergen Phl p $5 b$ with Reduced IgE-Binding Capacity but Conserved T Cell Reactivity“, sowie U. Herz Campus, Virchow-Klinikum Berlin, mit seiner Arbeit „A Human SCID Mouse Model for Allergic Immune Responses: Bacterial Superantigen Enhances Skin Inflammation and Suppresses IgE-Production“.

Auch die Arbeit von B. Wedi, Medizinische Hochschule Hannover, mit dem Titel „Delayed eosinophil programmed cell death in vitro: A common feature of inhalant allergy and extrinsic atopic dermatitis" erhielt den Herbert-Herxheimer-Förderpreis.

\section{Karl-Hansen-Gedächtnispreis}

Der Karl-Hansen-Gedächtnispreis 1999 wendet sich speziell an Wissenschaftler aus dem deutschen Sprachraum. Der Preis zeichnet eine im Verleihungszeitraum Oktober 1996 bis Juni 1999 eingereichte oder erschienene umfangreichere Originalarbeit oder Habilitationsschrift mit besonderer wissenschaftlicher Qualität in deutscher Sprache aus, die ebenfalls einen besonderen wissenschaftlichen Beitrag auf dem Gebiet der Allergologie und klinischen Immunologie darstellt.

Die Jury entschied sich in diesem Jahr für die Publikation von J. Elsner, Medizinische Hochschule Hannover, „Zur Modulation von Effektormechanismen und Antigenstrukturen eosinophiler Granulozyten durch Anaphylatoxine und Chemokine".

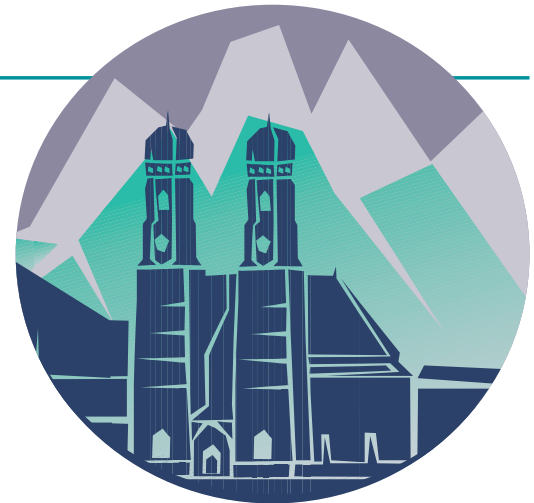

Clemens von PirquetStipendium

Das Clemens von Pirquet-Stipendium wird für die beste innerhalb eines dreijährigen Intervalls - diesmal von Oktober 1996 bis zum Juni 1999 - fertiggestellte Dissertationsschrift auf dem Gebiet der Allergologie und klinischen Immunologie vergeben. Die DGAI verlieh diesmal den Preis zu gleichen Teilen an U. Raap, Medizinische Hochschule Hannover, für ihre Arbeit „Untersuchungen zum programmierten Zelltod peripherer eosinophiler Granulozyten in vitro" und G. Reinhard, Medizinische Fakultät der Universität Bonn, für seine Arbeit „Untersuchungen zur intrazellulären Produktion von T-Helfer-1- und T-Helfer-2Zytokinen während der normalen humanen Schwangerschaft".

\section{Karl-Hansen-Medaille}

Die höchste Auszeichnung der Deutschen Gesellschaft für Allergologie und klinische Immunologie ist die Karl-Hansen-Medaille. Sie wird Forschern für ihr Lebenswerk in dem Bereich der Allergologie und klinischen Immunologie verliehen.

Es ist guter Brauch, diese Auszeichnung einem Deutschen und einem Forscher aus dem Ausland zu überreichen. Die deutschen Wissenschaflter sind in diesem Jahr Prof. Klaus Rother und Prof. Ursula Rother. Die Auszeichnung für die international $\mathrm{zu}$ ehrende Persönlichkeit geht an Prof. Terumasa Miyamoto aus Tokio und wird im Mai 2000 anläßlich eines internationalen Symposiums in Japan übergeben. 